\title{
EL SISTEMA MONETARIO GRIEGO Y SUS DERIVACIONES A OTROS SISTEMAS DE LA ANTIGÜEDAD MEDITERRÁNEA
}

\section{THE GREEK MONETARY SYSTEM AND ITS DERIVATIONS OVER OTHER ANCIENT MEDITERRANEAN SYSTEMS}

\author{
Ana VICO BELMONTE \\ Universidad Rey Juan Carlos \\ José María DE FRANCISCO OLMOS \\ Universidad Complutense de Madrid
}

\begin{abstract}
Resumen: Una de las principales características de la numismática griega son las grandes diferencias que encontramos entre las emisiones de las poleis, que no coincidían ni en el mensaje iconográfico de sus tipos, ni tan siquiera en el patrón métrico de sus valores. Estas diferencias aún así quedaban reflejadas en sistemas de intercambios que los santuarios estipulaban dando así una oficialidad al cambio.
\end{abstract}

Palabras clave: Metrología, propaganda, moneda, valor, patrón peso.
Abstract: One of the main features of the Greek currency are the big differences between emissions of the polis, which did not match either in their iconographic message types, not even in the met- rical pattern of their values. These differences were reflected in exchange systems ruled by the main sanctuaries that shrines stipu- lated thus giving official status to change.

Keywords: Metrology, propaganda, currency, value, weight pattern.

\section{INTRODUCCIÓN AL SISTEMA DE VALORES GRIEGO. SI- GLOS VII Y VI A. C.}

El origen de la moneda está, como no podía ser de otra manera, íntimamente ligado a la razón principal de su función, el intercambio económico, un área de investigación todavía llena de polémica para científicos y estudiosos que buscan respuestas y evidencias, difíciles de consensuar. Desde una perspectiva global, su 
origen nos lleva a relacionarlo directamente con el periodo referido como de colonizaciones del Mediterráneo en el que las poleis que componían la Hélade, fundaban colonias en tierras alejadas para fomentar su desarrollo económico y social ${ }^{1}$.

Una de las características de la cultura griega es el amplio número de poleis o ciudades-estado que englobaba. Cada ciudad, a modo de Estados independientes, tenía la potestad de fabricar su propia moneda escogiendo el peso, valor y forma que gustase ${ }^{2}$. Por ello y ante la no estandarización de los tipos monetales, al contrario de lo que ocurrirá posteriormente en Roma, y en combinación con la organización política de la Hélade compuesta por esa multiplicidad de poleis, la moneda griega se convirtió en una gran henteleia de tipos y cecas ${ }^{3}$.

Los inicios de la era numismática se sitúan entre los territorios de los antiguos reinos de Lidia y Jonia entre los años 650-625 a. C. ${ }^{4}$, con un uso de las monedas como meras pepitas de electro extraídas de ríos adyacentes como el Pacto$10^{5}$. Aunque estas pepitas no se acuñaban, sí seguían un sistema de pesos propio que medía su valor y que no tenía por qué coincidir con el de otras Ciudades Estado vecinas. Su uso en las transacciones se extendió con gran celeridad por la Hélade, aprovechando el mar Mediterráneo como principal vía de difusión y encontrando en las monedas la herramienta perfecta para perfeccionar y ajustar los valores de los diferentes niveles de transacción, desde aquéllos intercambios estatales a gran escala a aquéllos que se realizaban en un comercio menor o de menor esca$1 a^{6}$.

${ }^{1}$ E. BABELON, Le Traité des monnaies grecques et romaines, París, 1910-1932.

2 J. BABELON, La Numismatique Antique, París, 1964; B. V. HEAD, Historia Nummorum. A manual of Greek Numismatics, Londres, 1963; C. M. KRAAY, Archaic and Classical Greek Coins, Nueva York, 1976.

${ }^{3}$ Tradicionalmente se ha englobado dentro de la numismática griega a un amplio abanico temporal y geográfico de ciudades y culturas antiguas emisoras de moneda, que abarcan desde las costas nororientales de la Península Ibérica y el sur de Francia hasta el valle del Indo, con todas las colonias griegas emplazadas en el Mediterráneo, las cecas aqueménidas en Asia que demuestran en sus acuñaciones la gran influencia helena y finalmente la expansión alejandrina por el Valle del Indo. La Hélade no acuñó de forma general como hicieron civilizaciones posteriores. Sino que las emisiones se realizaban a nombre de poleis, en ocasiones de reyes, y como marco más amplio a nombre de ligas bien políticas, militares o religiosas.

4 "El primero de todos en acuñar moneda fue Fidón de Argos, en Egina, y no sólo aportó la moneda, sino que además, retirando todos los espetones (obeliskoi), los dedicó a Hera en Argos". (Etymologicum Magnum, 613, 12-15). T. GAISFORD (ed.), Etymologicum Magnum, Ámsterdam, 1965 ( $2^{\mathrm{a}}$ edición), [ $1^{\mathrm{a}}$ ed. Oxford, 1848]. P. RANCE, "The Etymologiucum Magnum and the Fragment of Urbicius", Greek, Roman, and Byzantine Studies, 47 (2007), pp. 193-224.

${ }^{5}$ D. SEAR, Greek coins and their values, 2 vols, Londres, 1978 (reedición 2004).

6 "Los lidios, por otra parte, tienen costumbres muy similares a las de los griegos, con la excepción de que prostituyen a sus hijas. Fueron los primeros hombres que sepamos, que acuñaron y 

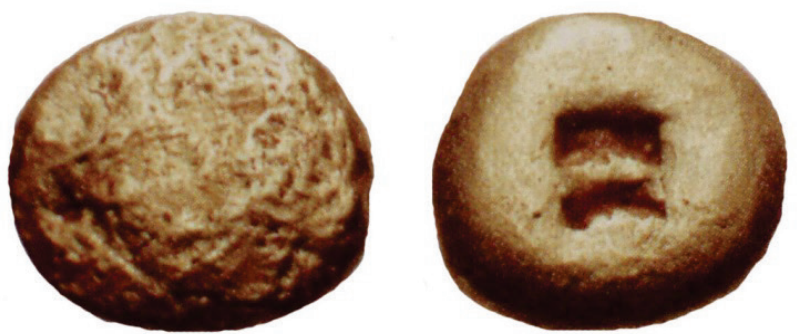

Ilustración 1. Pepita de electro procedente del área de Asía Menor (aprox. 650 a. C.).

Con el tiempo, la evolución de las pepitas hacia formas más estandarizadas y regulares, llevaron a su vez a incluir marcas que servían para identificar orígenes o emisiones. Fue entonces cuando la iconografía pasó a incorporarse en las piezas monetales y las monedas incorporar escenas más complejas y desarrolladas. Como cada poleis realizaba sus propias emisiones, elegía también de forma particular la representación que inscribiría en ellas, ya fueran sus dioses tutelares, su mito fundacional, aquello que representaba mejor su economía, etc. Así cuando el uso de las monedas se difundió a través de las innumerables transacciones económicas en las que participaba, el elemento representado se convertía en símbolo y emblema del Estado emisor, pues lo representaba en un soporte relevante que se identificaba una ciudad y garantizaba el valor otorgado por un gobierno a esa moneda ${ }^{7}$. Este mensaje que servía para dar fe del valor otorgado a las monedas y a la iconografía que presentaban, pues enlaza directamente con otra de las funciones que se le ha dado a la moneda: su valor propagandístico, ya que a lo largo de la Historia encontramos una enorme cantidad de casos en los que los tipos monetales servirán como vía de difusión de la propaganda estatal con un resultado muy efectivo, puesto que su difusión geográficamente hablando era enorme ${ }^{8}$.

utilizaron monedas de oro y plata y, asimismo, los primeros en comerciar al por menor". (Heródoto, I, 94; traducción utilizada: HERODOTO, Historia. Obra completa, ed. Gredos, Madrid, 2006).

7 S. FRANKENSTEIN, "Power and Propaganda", Mesopotamia, 7 (1979), pp. 263-294; GARNSEY, K. et alli, Trade in the Ancient Economy, Berkeley, 1983.

${ }^{8}$ En los momentos arcaicos, los clanes eran los que mantenían el poder dentro de las ciudades, así que en las primeras emisiones encontramos una gran variedad de tipos, aunque en épocas más tardías se produjo una cierta unificación. Así mismo, estas primeras emisiones suelen ser anepígrafas hasta que posteriormente se introdujeron abreviaturas y palabras completas, que tienden a ser étnicos o nombres de ciudades. Hasta épocas muy posteriores no encontraremos nombres de reyes como por ejemplo en la moneda macedónica o siciliana. En la sociedad griega, las capacidades y responsabilidades militares residían en lo más alto de su jerarquía social, que estaba en manos de una elite sobre la que recaía la responsabilidad de desarrollar la lucha en el campo de batalla, desempeñando una función de determinante iniciativa y organización del combate. Esta labor era además, proporcional a la función que en materia política y económica ostentaban dentro de su polis. 
Los templos griegos parece que fueron los primeros centros encargados de la administración así como del control de las acuñaciones monetales, peso-valor de las monedas, extensión de la emisión etc., debemos pensar que la elección de tipos debía depender en gran medida de sus decisiones, aunque muy estrechamente ligadas al poder político de la zona. Mientras tanto la estructura política de las poleis griegas iniciada en el siglo VIII a. C., condujo progresivamente a la fijación de nuevas relaciones comunitarias, trayendo consigo diferentes sistemas métricos e infinidad de tipos monetales. Así, prácticamente desde sus comienzos y hasta la aparición del denario romano, la moneda griega ejerció de patrón monetal en las transacciones comerciales que se realizaban a lo largo de las costas del Mediterráneo oriental y sur de Italia, extendiéndose hasta los confines de Occidente e incluso el norte de Europa. A modo de preámbulo indicaremos que fue el sistema ático el que rápidamente emergió como la medida a seguir y sus monedas fueron respetadas en la Antigüedad debido a las pocas alteraciones que se realizaron sobre la cantidad y calidad de plata que las componían ${ }^{9}$.

\section{EL ORIGEN DE LA MONEDA COMO JUSTIFICACIÓN DE SU} VALOR

Hasta el momento se apuntan diversas vertientes de opinión en las que basar un origen de la moneda fundamentadas en distintas actividades, tales como el pago de las soldadas, los impuestos, motivos religiosos o fruto de la actividad comercial. La gran incógnita es por qué se dio el enorme paso en esa sociedad de en vez de intercambiar bienes entre sí utilizar un nuevo invento, la moneda, que pronto alcanzaría una importancia enorme y cambiaría muchas prácticas de las sociedades que la asumieron como propia.

Por ello resulta fundamental entender el concepto que tenían de moneda en la Grecia antigua y el papel que representaba dentro de su sociedad. Para ello vamos a ver las diferentes hipótesis sobre su origen, cuál fue la necesidad que llevó a los griegos a acuñar la primera moneda y la función inicial que tuvo. Hoy día las vemos de forma diferente, la moneda es el dinero con menos valor. Pero en la Grecia antigua no era así, la moneda tenía una gran relevancia dentro de su socie-

${ }^{9}$ En torno a mediados del siglo VI, la práctica de emisión de moneda se extendió por todo Grecia, comenzando en la década del 550 a acuñar un gran número de monedas. No había electro en la zona de la Grecia europea por lo que sus habitantes nuca acuñaron con este metal, su lugar lo ocupó la plata, las primeras emisiones de Egina, Atenas, Corinto y las ciudades eubeas de Chalkis, Eretria y Karystos son todas de esta época. 
dad y no sólo por el valor intrínseco que portaban al estar realizadas sobre metales nobles, sino también por la entidad representativa que se le imprimía dentro de cada poleis y que explicaremos a continuación. Entonces, ¿para qué se inventaron las monedas? Las hipótesis más actuales y en las que nosotros vemos más lógica en los razonamientos hablan de la invención de ella para dar salida a metales preciosos desde el órgano estatal. No podemos pensar que la moneda se inventase para facilitar compras a pequeña escala, pero sí entender que de un comercio a gran escala, en el que los metales preciosos jugaban un papel protagonista por su interés en los intercambios, se evolucionó a un formato de pagos que generando más valores que los que los lingotes representaban daban acceso al intercambio de mayor número de participantes de diferentes potenciales.

Lo que sí parece claro es que el metal precioso pasó de ser un elemento inalcanzable para la mayor parte de la población a un valor de intercambio, accesible y funcional para una gran mayoría de ella, que en virtud de las necesidades de la transacción utilizaron los valores en virtud de su metal y peso. Por ello entendemos que nos es coincidencia que la aparición de la moneda coincida con la gran expansión colonial griega por el Mediterráneo, que fue uno de los sucesos que engrandecieron y provocaron el que la cultura griega evolucionase a lo que posteriormente llegó a ser, una gran semilla cultural para tantas culturas. Se tiene constancia de que desde época arcaica, los griegos transportaban plata a Egipto, donde recibían a cambio grano, lo cual fue su primer interés dentro de este intercambio. Así que tenemos que Egipto cambia grano por metales al peso y materiales exóticos.
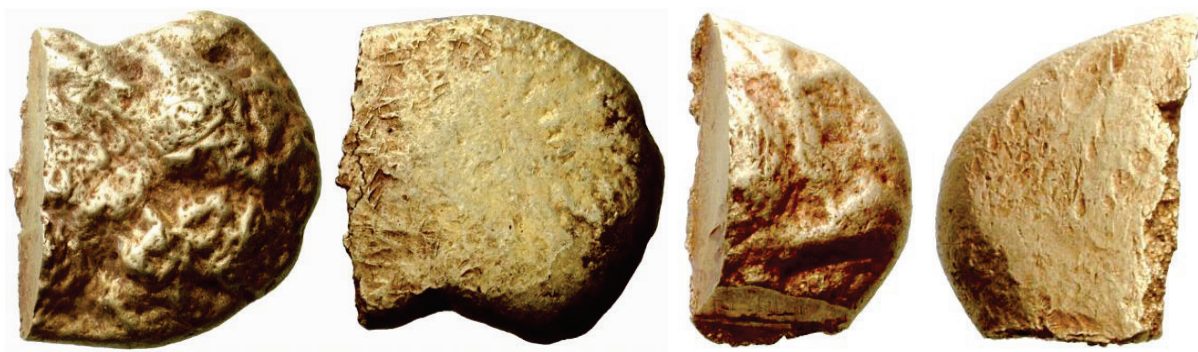

Ilustración 2. Lingotes de electro hallados en la zona del Mar Negro donde se aprecia los cortes limpios de cizalla para ajustar su valor. (Pesos: EL., 13,55 g.; EL., 71,11 g.).

Hay que tener en cuenta, que el metal en esta época representaba el máximo exponente del poder económico, íntimamente ligado con el político, el religioso y por tanto el social. Sin embargo la extensión del patrón moneda no sería posible en una cultura cuya base económica no girase en torno al comercio, pues la aceptación de un metal a cambio de comida por ejemplo no puede darse si no es en 
una sociedad mínimamente jerarquizada en la que la separación y demarcación de clases no fuese un distintivo social.

Ante la cuestión del origen de la moneda y la necesidad de su uso, actualmente, existen varias hipótesis según la razón que se da a esa función inicial ${ }^{10}$. No pensamos descifrar aquí un tema tan controvertido como el origen de la moneda, ni siquiera pretendemos postular una hipótesis sobre el origen de ella, pero sí queremos para justificar su uso y por tanto el desarrollo de una metrología para realizar los pagos, reflexionar el porqué de su necesidad y por tanto del inicio de su uso. Por ello, de forma somera y superficial incluimos las cuatro hipótesis más aducidas en la bibliografía especialiada:

- H-1. ORIGEN MILITAR. Hay autores ${ }^{11}$ que postulan esta razón como origen justificando la conveniencia de pagar a los soldados y mercenarios con estas piezas mejor que en especie o con objetos valioso tal y como nos narraba Homero en la Odisea (siglo VIII a. C.). Sin embargo esta teoría se ve descartada al comprobar que el fenómeno del mercenariado griego cuyas primeras acciones se desarrollaron en Egipto ocurrieron en fechas algo posteriores a finales del siglo VII a. C., solo se tienen datos de ellas poco después de principios del VI a. C.

- H-2. ORIGEN FISCAL. De modo similar al de los mercenarios y/o soldados estaría esta hipótesis que se ve rechazada cuando entendemos que en Grecia la estructura social oligárquica que quiere decir que el poder reside en los nobles, dividía los territorios en las tierras de éstos y no pagaban tributo a reyes cada uno recogía sus beneficios o pérdidas y sus obligaciones para con la ciudad se mantenían dentro de las labores de defensa y participación en política pero no en sustento económico. El impuesto más antiguo del que se tienen referencias data de 428-427 a. C. cuando la rebelión de Mitilene complicó la estrategia ateniense y se aplicó una Eisphora: impuesto directo extraordinario aplicado a los ciudadanos para los casos de necesi-

${ }^{10}$ S. BOUTIN, Catalogue des Monnaies Grecques Antiques de l'Ancienne Collection Pozzi. Monnaies frappés en Europa, Maastricht, 1979; A. DOMÍNGUEZ MONEDERO, "La polis y la expansión colonial griega. Siglos VIII-VI", Historia Universal Antigua-6, Madrid, 1993 y. B. V. HEAD. Historia Nummorum: A manual of Greek Numismatics. Londres, 1977; C. J. HOWGEGO, "Why the Ancient States strike Coins?" y Ancient History from Coins, Londres, 1995, The Numismatic Chronicle, Londres, 1990; G. K. JENKINS, Monnaies Grecques, Friburgo, 1972; C. M. KRAAY, Archaic and Classical Greek Coins, Londres, 1976. L. KURKE, Coins, bodies, games and gold: The Politics of Meaning in Archaic Greece, Nueva Jersey, 1999; N. PARÍSE, Origen de la moneda, Barcelona, 1998; F. REBUFFAT, La monnaie dans l'Antiquité, París, 1996, pp. 69-70.

${ }^{11}$ Sirva de ejemplo: A. MÖLLER, Naukratis; Trade in Archaic Greece, Oxford, 2000. 
dad, pero ni siquiera en los difíciles años de la Guerra del Peloponeso se tuvo la intención de aplicarlo de forma permanente.

- H-3. ORIGEN RELIGIOSO. Uno de sus primeros defensores fue Bernhard Laum, quien en $1924^{12}$ postuló la teoría de un posible origen religioso de las monedas, a partir de los diferentes hallazgos en templos y las coincidencias de nomenclaturas como los asadores llamados también óbolos y que eran objetos rituales en los sacrificios. De hecho en los textos homéricos se les referencia como instrumentos con el que después de asar las vísceras se asaba la carne de las víctimas sacrificadas. Así que no parece que el óbolo o asador pasara de instrumento de sacrificio a instrumento de valoración. Pero la coincidencia del nombre y el que 6 óbolos se llamen dracma, no parece responder más que a una razón filológica en la que dracma significa grupo o puñado. La reincidencia de hallazgos de moneda templos es constante, algunos tan relevantes como el de la base central del templo de Artemis en Éfeso, lo que sin duda ayuda a encauzar estas teorías ${ }^{13}$, que posteriormente se vieron fortalecidas con la localización de monedas en puertos comerciales del Mediterráneo oriental con espacios donde se desarrollaba la prostitución sagrada ha llevado a que esta hipótesis alcanzara mayor peso, pero a nuestro parecer no termina de representar una justificación única a su función.

- H-4. COMERCIAL. En ella se parte de la premisa de que las transacciones diarias en los inicios del periodo monetal, continuó manteniendo un comercio de trueque a pesar de la existencia de la moneda, pues sus valores eran tan altos que no servían para transacciones cotidianas internas. Sin embargo, en términos de un comercio a gran escala Milne ${ }^{14}$ asume y defiende una importante conexión entre la invención de la moneda y la emergencia del comercio mediterráneo. Ésta última hipótesis ha sido también consecutivamente refutada como apreciamos en reflexiones como la de Servet ${ }^{15}$ :

${ }^{12}$ B. LAUM, Heiliges Geld. Eine historische Untersuchung über den sakralen Ursprung des Geldes, Tübingen, 1924. Una teoría contestada y refutada en A. WITTENBURG, Bernhard Laum und der sakrale Ursprung des GELDES, H. FLASHAR, Altertumswissenschaft in den 20er Jahren: Neue Fragen und Impulse, Stuttgart, 1995, pp. 259-274.

13 A. DOMINGUEZ MONEDERO, Comercio, santuarios y moneda en la Grecia arcaica", en Atti del Convegno Internazionale: Moneta e Mercanti Banchieri; I precedenti greci e romani dell'Euro, Cividale di Friuli, 2003.

${ }^{14}$ J. G. MILNE, "Two notes on greek coin dies", Numismatic Chronicle, 1922, pp. 43-48. Y también en "Notes on the Oxford Collections", Numismatic Chronicle, 1940.

${ }^{15}$ J. M. SERVET, Nomismata. Etat et origines de la monnaie, Lyon, 1984. 
"Toutefois son idée maîtresse, de trouver les origines des premières pièces helléniques dans les pratiques rituelles, c'est-à-dire hors de la sphère du commerce, demeure fort pertinent" ${ }^{\prime \prime}$. Ciertamente la moneda surge en Grecia y no es invento fenicio, máximos representantes en la Antigüedad del comercio. Pero esto no quiere decir ni que los fenicios no usasen los metales para sus transacciones comerciales, ni que la moneda se inventase para dar cambio a los mercaderes. Según esta corriente de pensamiento, la moneda debe verse como un medio que facilitó el intercambio exterior e interior, pues también se ha sugerido que la invención podría estar dentro de los contextos de competencias entre las poleis, el pago a mercenarios y como símbolo de soberanía estatal. Pero las monedas tenían demasiado valor para usarse diariamente.

Desde nuestra perspectiva las hipótesis de Milne son acertadas pero dentro de otros parámetros, en un comercio superior, el desarrollado por los estados y que intercambiaban metales preciosos en forma de lingotes con monedas, puede que para ajustar más los valores de las transacciones. Pero esto no es más que una hipótesis que nosotros secundamos como la más posible a merced de los datos recogidos hasta el día de hoy y nos viene avalada por su coincidencia temporal con la gran expansión colonial griega y se puede fundamentar con los resultados de las excavaciones arqueológicas realizadas en Egipto y Próximo Oriente donde han aparecido infinidad de monedas griegas. Es casi el mismo concepto que daba Milne pero un punto más alto, un invento estatal para intercambios estatales.

Es decir, la moneda podría situarse como el último eslabón en la evolución en ese comercio de metales precioso, que en virtud de unas necesidades surgidas por el propio desarrollo económico de las poleis, evolucionan hacia formas de pagos más pequeñas y por tanto económicamente, más evolucionadas para dar servicio también dentro del comercio interno de las poleis y no sólo a esa gran escala que suponían los intercambios entre ciudades que en definitiva se mantenían como a nivel interestatal. Tal y como el propio Aristóteles citó un par de siglos más tarde, la invención de la moneda dio lugar a la posibilidad de realizar intercambios comerciales justos, en los que todo tenía un mismo valor y no se hallaba la dificultad de realizar el intercambio por elementos que podían llevar a

${ }^{16}$ SERVET, op. cit. nota 9, p. 93. Así como en A. DOMÍNGUEZ MONEDERO, "La moneda de los dioses: monedas y santuarios en Grecia", en XIII Congreso Internacional de Numismática, Madrid, 2005, p. 227, nota 7. 
la disconformidad en cuanto a diferir en la igualdad de su valor. El texto de Aristóteles sobre el origen y función de la moneda, dice así:

Esto va bien, por lo tanto, también con las otras artes; porque habrían dejado de existir si el elemento activo no produjese y no recibiese el equivalente en cantidad y calidad de lo que recibe el elemento pasivo. Porque una asociación para el intercambio de servicios no se forma entre dos médicos, sino entre un médico y un granjero y generalmente entre personas que son diferentes y pueden ser desiguales, aunque en ese caso hay que tender a igualarlos. Por ello, todos los artículos intercambiados deben poder ser comparados del mismo modo. Es para cumplir este requisito para lo que los hombres han introducido la moneda. La moneda constituye una especie de término medio (méson), porque es una medida para todas las cosas, y así de su valor superior o inferior, es decir, por ejemplo, cuántos zapatos equivalen a una casa o a una determinada cantidad de comida. Así pues, del mismo modo que puede establecerse una relación entre un arquitecto y un zapatero, del mismo modo puede determinarse cuántos zapatos hacen una casa o una determinada cantidad de comida; porque sin esta proporción recíproca, no puede haber intercambio ni asociación; y éstos no pueden asegurarse a menos que los artículos en cuestión sean iguales en algún sentido. Es, por lo tanto, necesario, que todos los artículos sean medidos de acuerdo con una sola unidad, tal y como se ha dicho antes. Y esta unidad, en realidad, es la demanda, que es lo que mantiene todo unido, puesto que si los hombres dejan de tener necesidades o si sus necesidades cambian, el intercambio ya no continuará, o lo hará en diferentes términos. Pero la demanda ha llegado a ser representada convencionalmente por la moneda; es por ello por lo que a la moneda se la llama nomisma, porque no existe por naturaleza sino por costumbre (nomos) y puede alterarse o hacerla inútil a voluntad. Habrá, por lo tanto, proporción recíproca cuando los productos hayan sido igualados, de tal modo que la relación que existe entre un granjero y un zapatero sea la misma que hay entre el producto del zapatero y el producto del granjero. [...]

Ahora, la moneda nos sirve también como garantía de intercambio en el futuro: suponiendo que no necesitásemos nada ahora, asegura que el intercambio será posible cuando surja una necesidad, porque cumple el requisito de algo que podemos entregar como pago a cambio de la cosa que necesitemos. La moneda, es cierto, es susceptible de la misma fluctuación en la demanda que otros artículos, porque su capacidad de compra varía según las épocas; sin embargo, tiende a ser comparativamente constante. Por ello, lo más adecuado es que todos los artículos mantengan sus precios fijos; esto asegurará que el intercambio y, por consiguiente, la asociación, serán siempre posibles. La moneda, por lo tanto, sirve como el medio que hace las cosas conmensurables y las reduce así a la igualdad. Si no hubiese intercambio no habría asociación, y no puede haber intercambio sin igualdad, y no hay igualdad sin conmensurabilidad. Aunque, empero, es imposible para las cosas muy diferentes llegar a ser conmensurables en sentido estricto, nuestra demanda proporciona una medida común lo suficientemente adecuada para fines prácticos. Debe, pues, existir alguna unidad y ésta debe ser aceptada por acuerdo (que es por lo que se la llama nomisma); porque tal unidad hace todas las cosas conmensurables, puesto que todas las cosas pueden ser medidas por la moneda. Sea A una casa, B diez minas y $\mathrm{C}$ un lecho. Entonces $\mathrm{A}=\mathrm{B} / 2$ (suponiendo que la casa valga, o sea igual, a cinco minas), y $\mathrm{C}$ (el lecho) $=\mathrm{B} / 10$; queda ahora claro cuántos lechos son 
iguales a una casa, a saber, cinco. Está claro que antes de que existiese la moneda era así como se había establecido la relación del intercambio - cinco lechos por una casa - puesto que no hay una diferencia real entre eso y el precio de cinco lechos por una casa.

Aristóteles, Ética a Nicómaco, V, 8 .

Ante esta exposición de hipótesis y reflexiones puede apreciarse que nuestra posición se centra por tanto, en línea con la cuarta hipótesis expuesta, en la que se basa el origen de la moneda en la actividad comercial. Realmente, siempre que nos hemos planteado un origen comercial en la invención de la moneda se apuntaba rápidamente una contradicción, si era tan necesaria para las transacciones económicas, ¿cómo podía ser que un pueblo tan mercante como el fenicio no hubiese desarrollado ya este método de pago?. Sin embargo, esto se debe a que durante mucho tiempo se ha mantenido la idea equivocada de que la cultura fenicia realizaba sus intercambios económicos únicamente por medio del trueque con el resto de las culturas del Mediterráneo, cuando cada vez se tiene más certeza sobre la existencia de un comercio entre éstos y los pueblos de las tierras del interior del Próximo Oriente como los Neo-asirios, en cuyas transacciones ya se mantenía un patrón plata que fijaba los precios de los bienes u objetos en tránsito ${ }^{17}$. La diferencia entre un comercio y otro en cada punta del Mediterráneo no tiene otra causa que el grado de desarrollo de la actividad económica, acompañada de una estructura social lo suficientemente "amplia" y desarrollada, como para admitir un patrón de intercambio metálico y sobre todo unos intereses económicos más allá de lo que suponen los bienes de necesidad vital en ambas partes del intercambio. Así que aun teniendo unos precedentes en lo que hoy conocemos como las minas, es en Grecia donde tenemos que buscar, como ya es sabido por todos, la invención de la moneda como medio de pago.

En la moneda actual encontramos los emblemas de representación del Estado que la acuña, garantizando su valor y respaldando su oficialidad. Sin embargo, este carácter no puede buscarse en la moneda antigua, ya que era su propio peso el que marcaba su valor. Por lo que ignorando la necesidad de garantizar un valor determinado en las monedas, hemos de buscar una razón que explique los tipos escogidos para cada acuñación. El resultado, puede darnos con la teoría de que cada poleis marca en sus monedas los emblemas propios de cada ciudad para constatar quién las emite. En este caso cada una de las metrópolis extenderá por sus colonias las monedas que darán validez a sus transacciones. Otro elemento

${ }^{17}$ S. FRANKENSTEIN, "Power and Propaganda", Mesopotamia, 7 (1979), pp. 263-294; K. GARNSEY, et alli, Trade in the Ancient Economy, Berkeley, 1983. 
que nos ayuda a respaldar esta hipótesis es por tanto la iconografía, que nos muestra una simbología diversa entre las representaciones que figuran en las emisiones en oro o en plata cuya circulación era fuera de la poleis, que las realizadas en bronce cuya circulación era dentro de la ciudad y su chora. Por tanto vemos cómo en virtud de su uso cambia también el mensaje a representar ${ }^{18}$.

Por otro lado y como es obvio, cuanto más pura era la plata de las piezas emitidas más demandada era la pieza, con lo que los intereses comerciales podían verse favorecidos por determinadas emisiones, como es el caso de la moneda ateniense, cuya plata, bien sabido es por todos, era una de las más puras y su moneda de las más deseadas por el generoso peso (en torno a los cuatro gramos por dracma) que la métrica ática presentaba frente a la resto de los patrones.

\section{SISTEMA MONETARIO GRIEGO}

En prácticamente todas las culturas antiguas bañadas por el mar Mediterráneo encontramos objetos premonetales con función de dinero, en algunos casos incluso con la consideración de "agalmata" 19 , lo que provocó un paso a una economía monetizada tras la aparición de ésta. La única cultura que parece que tardó más en entrar en este sistema fue Cartago, seguramente por la ausencia de estructuras socio-económicas que lo requerían, como en el resto de culturas que por influencia y relaciones comerciales con sociedades donde ya estaba implantado lo adoptaron.

Entre los objetos que consideramos como dinero premonetal, mientras buscamos un uso para ellos, encontramos dos tipos aquellas que servían de intercam-

\footnotetext{
18 Continuando la teoría que cada poleis incluye en sus emisiones "emblemas representativos" encontramos un ejemplo interesante en la moneda de plata ateniense de época clásica, en cuyo anverso se representa la cabeza de Atenea galeada y con rasgos arcaizantes. Un tipo que no cambiará, aunque sí sufrió diversas matizaciones y evoluciones, que poco tienen que ver con lo que encontramos en la escultura de esta misma época o incluso en las piezas numismáticas coetáneas acuñadas por otras cecas. Lo que está claro es que en Atenas en el siglo V a. C. encontramos el suficiente desarrollo tecnológico y artístico como para representar escenas de mayor naturalismo y espontaneidad con pleno abandono del hieratismo arcaico y acercarnos así a las calidades artísticas que encontramos en la moneda siracusana por ejemplo. Es entonces cuando las lecturas podrían apuntar, no a una falta de conocimiento que no permitiese la introducción de tipos con un estilo más avanzado. Sino una intencionalidad de representar algo, que en este caso podría ser una escultura arcaica. Esto enlaza directamente con las teorías que apuntan la representación de una escultura que Gitíadas realizó para la ciudad de Atenas fundida en bronce.

19 Agalmata: objetos que resultaban socialmente como signos de posesión privilegiada y finalmente se situaron como reconocidos signos externos de riqueza para la sociedad. Sin embargo debemos matizar que son diferentes de los signos circulantes que acabaron convirtiéndose en valores premonetales.
} 
bio y que casi son un modo más de trueque como las semillas o la sal. El otro tipo son aquellos útiles que debían representar un valor imaginario no conocido hoy como serían las plumas, las piedras, las conchas, la tela e incluso el metal que además de ser objetos apreciados por las altas esferas sociales para su disfrute, adorno o acaparamiento para exhibirlo como trofeo, no encontramos otra función por la que fueran tan solicitados ${ }^{20}$.

La aparición de la moneda otorgó un elemento que facilitó y estandarizó los intercambios. De hecho, la numismática griega antigua contaba con un sistema de valores estructurado a partir de metales y pesos. El valor de cada pieza venía dado por su propio peso y por tanto, por la cantidad de metal que portaban, sistematizando a partir de una unidad (estátera ${ }^{21}$ ), toda una serie de divisores (hekte, hemiekton, etc...). La difusión de la moneda trajo consigo el desarrollo de distintos patrones métricos y una estátera podía tener importantes variaciones de peso según las distintas zonas geográficas. Con el tiempo se abandonó el uso del electro y el sistema de valores se hizo trimetálico (oro, plata y bronce), estableciendo equivalencias entre las diferentes fracciones y metales. Tras su expansión por toda la Hélade, encontramos que cada poleis asumió sus propias emisiones y para sus representaciones monetales eligió tipos muy variados basados en su historia, mitología, economía, etc...

El valor de la moneda griega venía dado por su propio peso; tanto pesaba, tanto valía. Los nombres de las piezas se generaron a partir de una unidad: la dracma y a partir de ella se crearon divisores y múltiplos. Había diferentes sistemas para medir los valores según las zonas, que se diferenciaban porque cambiaban los pesos de las piezas e incluso los metales en los que se acuñaban. Así en el área de Asia Menor se acuñó con electro como hemos visto, por ser el más abundante. Mientras que en otras zonas donde lo que primaba era la plata, sus acuñaciones se realizaban en ella, siendo la isla de Egina la primera en emitir moneda argéntea.

A pesar de estas diferencias, todos los sistemas tenían equivalencias entre sí, Jean Babelon ${ }^{22}$, de hecho nos cuenta cómo a modo de un mercado de divisas ac-

${ }^{20}$ Para este tipo de objetos premonetales encontramos referida la palabra: Keimelion, que hacía alusión a aquéllos objetos que representaban las cosas de valor de una casa; metales, armas, lebetes, trípodes, etc., los cuales podían realizarse en cualquier metal precioso (oro, plata y bronce).

${ }^{21}$ El término estátera en sus orígenes venía a significar peso y se utilizó en el mundo griego como unidad de peso en las emisiones monetales desde su origen con acuñaciones sobre electro e incluso posteriormente con las de plata.

22 J. BABELON, La Numismatique Antique,París, 1964, pp. 27-28. 
tual, en el santuario panhelénico de Delfos se intercambiaba un tetróbolo egineta de 4,25 g. de plata por un dracma ático de 4,36 g. de plata; un dióbolo egineta de 2,12 g por un trióbolo ático de 2,18 g. y el óbolo egineta de 1,06 g. por el trihemióbolo ático de $1,09 \mathrm{~g}$. de plata. Esto es importantísimo, porque nos muestra que existía una comunidad económica y comercial en la Hélade, donde daba igual la moneda que se usara, ya que siempre estaba dentro del marco de intercambios monetarios aceptados por todos, que es lo que nos muestra el texto.

Por su parte, la moneda de oro en Grecia no era común, su valor era muy alto y por ello la emisión fue muy escasa. Sin ninguna duda, las acuñaciones en plata fueron las emisiones más prolíficas en la Grecia antigua, llegando a ser consideradas algunas de sus emisiones, como el patrón de intercambio más demandado de la Antigüedad. Es el caso de las tetradracmas atenienses, las famosas "emisiones de la lechuza" acuñadas en el siglo V a. C., y que dada la calidad y pureza del metal, se convirtieron en una de las piezas más demandadas en los intercambios comerciales de la época. Mientras que la pieza de bronce griega es, hoy por hoy, una gran desconocida dentro de la numismática antigua. Seguramente su poco valor y sobre todo la competencia que tiene con la atractiva espectacularidad de las emisiones en cualquiera de los otros dos metales, provoca una cierta falta de interés por parte de los investigadores y los coleccionistas, dando lugar a una ausencia importante de estudios sobre ella.

Las acuñaciones de bronce no fueron emisiones muy tardías, tal y como se venía diciendo hasta hace poco tiempo, sino que encontramos emisiones de este tipo de moneda fraccionaria ya desde el siglo $\mathrm{V}$ a. C. La laguna de conocimiento que representa la moneda de bronce griega llega a su máximo exponente cuando, no sólo vemos la falta de unanimidad en las cronologías, sino que incluso estamos ante piezas que no tienen denominación, por lo que nos referimos a ellas a partir de sus pesos o diámetros. Esto se debe a que dentro de las poleis no hallamos una misma estructuración métrica, por lo que dada su enorme cantidad de emisiones, resulta más sencillo referirse a ellas señalando únicamente el peso y metal que la soporta (por ejemplo: $Æ 12,5 \mathrm{~g}$.).

El escaso número de monografías que encontramos referentes a la moneda de bronce griega, seguramente nos hace tener un concepto erróneo de lo que sería la economía de la época. Sin embargo, sería justamente esta moneda, la que más circulase dentro de cada poleis y no las de oro o las grandes piezas de plata. A nuestro parecer, esta moneda fraccionaria es la que nos llevará a ver, según su abundancia y variedad, el desarrollo económico que habría dentro de cada una de las poleis o ciudades-estado, y por tanto, la que más nos ayudará a mostrar la 
realidad económica de cualquiera de ellas. Hasta hace muy poco se venía pensando que la moneda de bronce griega fue un fenómeno casi exclusivo del período Helenístico, sin embargo algunos estudios monográficos, nos han permitido ver y clasificar muchos ejemplares como de un momento bastante anterior ${ }^{23}$.

De cara a la denominación de las piezas, ya hemos mencionado que los nombres se generalizaron a partir de una unidad o pieza base: la dracma que equivalía a 6 óbolos, esta correspondencia viene dada por un sistema premonetal en el que los óbolos (inicialmente piezas de bronce con forma de punta de flecha) eran utilizados en las transacciones económicas y ya entonces al grupo de seis óbolos (obeloi) se le denominaba dracma.

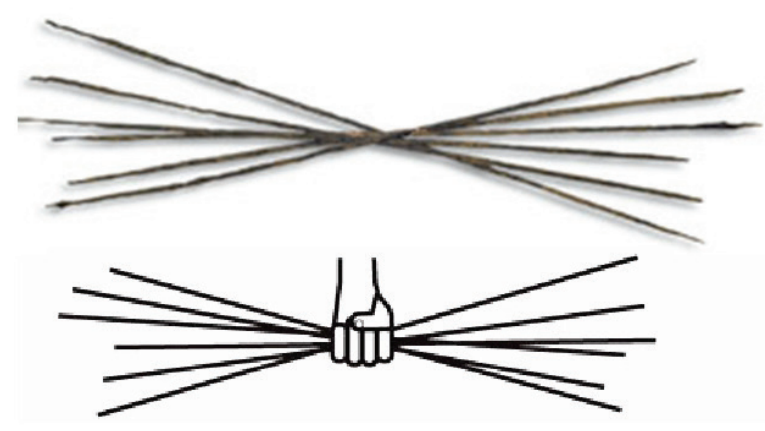

Ilustración 3. Representación de 6 obeloi equivalentes a un dracma.

\section{SISTEMAS MÉTRICOS EN LA GRECIA ANTIGUA}

Atendiendo a los sistemas métricos que localizamos en las monedas helenas, se definen dos patrones diferentes utilizados desde las primeras monedas emitidas, puesto que inicialmente se dio un sistema bimetálico en el cual el Estado no había fijado la relación entre los dos metales.

Hay diversas denominaciones dependiendo de su peso y el metal sobre el que se acuñaba pues el sistema monetal era trimetálico (oro, plata y bronce) y obviamente 4 gramos de plata valía más que 4 gramos de bronce pero menos que 4 gramos de oro. Para facilitar las transacciones existía una tabla de equivalencias con correspondencias entre piezas de diferentes metales donde lógicamente una pieza de oro se relacionaba con una más pesada de plata y otra más pesada aún de bronce. Así un gramo de oro equivalía a 13 gramos y 1/3 de plata. Mientras que

${ }^{23}$ VVAA, "Le Origini della Monetazione do Bronzo in Sicilia e in Magna Grecia", en Atti del VI Convegno del Centro Internazionale de Studi Numismatici, supplemento al vol. 25 degli anuali, Nápoles, 1977. 
un gramo de oro era igual a uno de electro y un gramo de electro correspondía a diez de plata.

Con estas relaciones de intercambio entendemos que la relación entre los metales no debía variar aunque sí sabemos que en alguna ocasión fluctuaba. Como ya hemos dicho la dracma (en torno a los 4 gramos de plata) era la unidad en la que se basaba el sistema monetario. La difusión de la moneda y la propia estructuración política de la Hélade propició la emergencia de diferentes sistemas métricos según el área de emisión, los patrones métricos utilizados variaron en pesos y equivalencias, esta variedad además favorecía el comercio.

Tras el estudio de los diferentes sistemas métricos nos encontramos con que las poleis griegas mantenían una gran diversidad metrológica en sus emisiones que sin duda, favoreció el desarrollo del comercio. Fueron varios los sistemas utilizados en el entorno mediterráneo, por ser el más repetido por los autores especializados, el que aquí presentamos es el equivalente a: $1 \underline{\text { talento }}=60 \mathrm{Minas}$. El cual podemos incluirlo como un sistema que actúa a modo de preámbulo al sistema monetal y que se utilizaba como denominación para las piezas en el oriente mediterráneo, pero según los patrones el más empleado fue el ático. En él los valores se marcaban siguiendo las siguientes equivalencias:

$$
\begin{aligned}
1 \text { Mina } & =100 \text { dracmas }(436,6 \text { g. }) . \\
1 \text { Talento } & =60 \text { Minas }=6000 \text { dracmas }
\end{aligned}
$$

Sin embargo, no debemos obviar que estas equivalencias en un momento inicial se hacían dentro de un sistema de cuenta en peso, por ello debemos tomarlo con muchas reservas. Con posterioridad a partir de la mina surgieron varios sistemas monetales pues de hecho vemos que en el área de la Hélade, la Mina se dividió en dracmas, pero a su vez de la Mina babilónica derivó el shekel y de la Mina Mediterránea surgió la litra y la libra.

Por otro lado encontramos otro sistema métrico basado en la estatera, la cual como ya se hay dicho en este trabajo significaba peso y cuya métrica se descomponía en una amplia escala de valores:

$\begin{array}{ll}\text { Estátera } & 1 \\ \text { Hemiestátera } & 1 / 2 \\ \text { Trite } & 1 / 3 \\ \text { Tetarte } & 1 / 4 \\ \text { Hecté } & 1 / 6 \\ \text { Hemibécton } & 1 / 12 \\ \text { Valores menores. } & \end{array}$




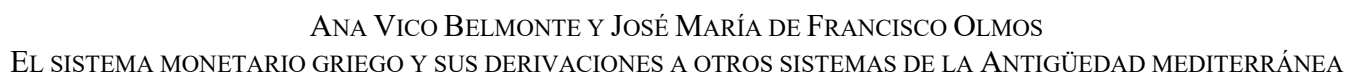

A partir de estos sistemas iniciales, encontramos un desarrollo de las métricas en los sistemas que cada ciudad implantaba para sus emisiones, utilizando los metales más abundantes de su entorno o más accesibles para ellos. La métrica e incluso los metales empleados fueron variando a lo largo del tiempo, lo cual unido a su iconografía presentaba una perfecta herramienta propagandística. Con lo que según la preponderancia política y económica de las diferentes poleis, la importancia de las monedas y por tanto las preferencias por el uso de unas u otras piezas cambiaba. A continuación exponemos los diferentes sistemas y denominaciones que encontramos en la Grecia antigua en virtud de épocas y zonas:

\section{DENOMINACIONES DEL SISTEMA DE ELECTRO EN LA} GRECIA ARCAICA

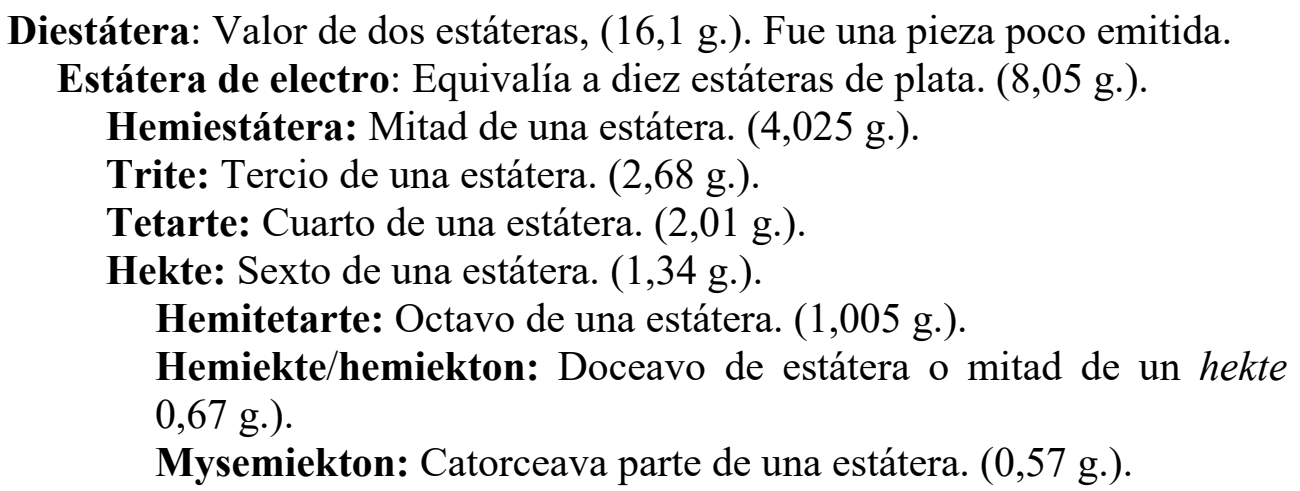

Este sistema está basado en el sistema metrológico lidio. Es decir, está marcado como el primer sistema desarrollado en la zona de Asia Menor donde se sitúa el inicio de los usos monetales y que parte del sistema métrico basado en la estatera, el cual posteriormente desembocará en uno de los más difundidos, el sistema ático. Aún así su inicio está basado en la unidad de electro, en el que una estátera de oro (o electro), equivalía a diez estáteras de plata (o lo que posteriormente serán veinte dracmas).

En cuanto a las denominaciones del sistema de la plata griega, encontramos una estandarización de los valores, abarcando opciones de grandes pagos con monedas de gran peso o valor y su división en monedas fraccionarias que llegaron a alcanzar valores realmente bajos para el estándar de plata. Su estructura y nomenclatura sigue unas pautas matemáticas, que sólo cambiaba según la poleis emisora en los pesos y cantidades de metal que portaban. Así se configuraban: 
Dodecadracma: Valor de doce dracmas $(50 \text { g. })^{24}$

Decadracma: Valor de diez dracmas (43 g.).

Octodracma: Valor de ocho dracmas (32 g.)

Pentadracma: Valor de cinco dracmas $(21,75$ g.).

Tetradracma: Valor de cuatro dracmas $(17,2 \mathrm{~g}$.).

Tridracma: Valor de tres dracmas (13,05 g.).

Didracma: Valor de dos dracmas $(8,6$ gr). También llamada estátera de plata.

Dracma: $1=6$ Óbolos (4,35 g.).

Pentóbolo: Valor de 5 óbolos, corresponde a 5/6 de dracma (3,625 g.).

Tetróbolo: Valor de 4 óbolos, corresponde a $2 / 3$ de dracma (2,90 g.).

Trióbolo /Hemidracma: Valor de 3 óbolos (2,19 g.).

Dióbolo: Valor de 2 óbolos, corresponde a 1/3 de dracma (1,46 g.).

Trihemióbolo: Valor de 1,5 óbolos, equivale a 1/4 de dracma (1,10 g.).

Óbolo: 1 . Equivale a $1 / 6$ de dracma $(0,73 \mathrm{~g}$.).

Tritetartemorion: $3 / 4$ de óbolo $(0,57 \mathrm{~g}$.).

Hemióbolo: $1 / 2$ óbolo ( 0,37 g.).

Trihemitetartemorion: $3 / 8$ de óbolo ( $0,28 \mathrm{~g}$.).

Tetartemorion: $1 / 4$ de óbolo $(0,19$ g. $)$.

Hemitartemorion: $1 / 8$ de óbolo $(0,09 \mathrm{~g}$.).

En cuanto a las denominaciones en bronce dentro de la antigua Grecia, debemos atender que la moneda de bronce era una moneda de necesidad cuya circulación se reducía exclusivamente al interior de las poleis y su chora circundante. No se trataba de una moneda importante por lo que lo único que de ella se esperaba era que cubriera con la función de pago encomendada. De hecho en muchas ocasiones dentro de la numismática griega nos encontramos que no conocemos la denominación de la pieza de bronce. La presencia de moneda fraccionaria en las economías de las poleis retrata su grado de evolución y complejidad, con lo que con el tiempo encontraremos sistemas métricos muy evolucionados y que incluso llegarán a ser la base del resto de valores monetales como en el caso de Roma. En el entorno heleno el sistema en bronce se estructuró así:

Dicalco: Valor de dos calcos y equivalía a un cuarto de óbolo (tetartemorion de plata).

Calco: Corresponde a un octavo de óbolo (hemitartemorion de plata).

Lepton: Sobre esta denominación quedan dudas sobre sus equivalencias pero se cita como un séptimo de calco.

${ }^{24}$ Los pesos señalados atienden al sistema metrológico ático. Sin embargo hemos de señalar que Solón cambió el sistema métrico monetal en Atenas, abandonando el patrón egineta en el que una mina eran 60 dracmas (Dracma $=4,32$ gramos), para adoptar el euboico en el que una mina son 100 dracmas. 
Asimismo en virtud de las áreas geográficas, y por tanto según los lugares de emisión, los patrones métricos utilizados podían variar en pesos y equivalencias. A continuación exponemos los sistemas más utilizados según las zonas ${ }^{25}$.

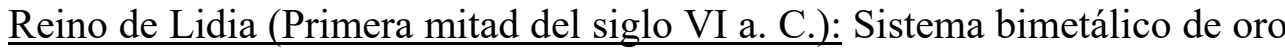
y plata ${ }^{26}$ :

AV.- Estátera de 8,05 g. con divisores de hasta 1/12 (hemihekton); la relación entre el oro y la plata es de $1=13(1 / 3)$.

AR.- Estátera de $11 \mathrm{~g}$.; su hemihekton equivale a 1/120 del de oro.

Jonia: Se mantiene el uso del electro con divisores de hasta 1/96 de estátera; a finales de siglo VI, se introduce la plata que favorece la aparición de patrones locales para cada taller:

Milesio: Estátera de 14,1 g.

Euboico: Estátera de 17,2 g.

Focense: Estátera de 16,1 g.

Fidoniano o Eginético: La dracma egineta pesaba 6,16 g., se amonedaba en didracmas o estáteras de 12,32 g. Se usó en Egina, Peloponeso, Beocia, Tesalia, Fócida parte de las Cícladas, Creta, etc..., fue un sistema muy difundido por el papel comercial de Egina; cabe la posibilidad de que su origen sea un patrón ponderal instituido por Fidón de Argos.

\footnotetext{
${ }^{25}$ Las monedas de oro de época clásica y helenística seguían los patrones métricos áticos o los impuestos por Alejandro III. Teniendo como excepción el sistema persa en el que un dárico pesaba 8,4 gramos.

${ }^{26}$ Cuando el reino de Lidia cayó en el 546 a. C. bajo dominio aqueménida, las ciudades griegas de Jonia se vieron obligadas a someterse al Imperio Persa. A diferencia de los lidios, los griegos habían continuado usando el electro en la mayoría de sus monedas (por esta época), emisiones de estáteras y 96 fracciones distintas. El uso de la plata se introdujo en los últimos años del siglo VI a. C. aunque parece haber jugado un papel sólo subsidiario de las emisiones más importantes de electro. Un gran número de cecas parecen haber sido las que lo acuñaron: Éfeso, Focea, Mileto entre otras, dependiendo de la zona hay distintos estándares y las estáteras. De todos ellos, el estándar foceo fue el que finalmente se adoptó debido a la extensión que tuvieron sus monedas de electro, las cuales los griegos asiáticos acuñaron hasta tiempos de Alejandro. Tres cecas se vieron principalmente envueltas en la acuñación de estas bellas monedas; Kyzikos, colonia milesia en el Mar de Mármara, emitió series de estáteras (de peso 16,1 g.) de las cuales se conocen más de doscientos tipos diferentes. La ceca jonia de Focea y Mytelene la ciudad de la isla de Lesbos, produjeron grandes series de hektai (sexto de estátera 2,6 g.) posiblemente en años alternativos. La producción de las dos cecas es fácilmente diferenciables pues las Focea nunca llevan tipos en el reverso.
} 
Ático: El estándar ático basado en la didracma de $8.2 \mathrm{~g}$. Y después en la tetradracma de 17.44 g., dracma de 4,36 g.; y óbolo de 0,72 g. Fue adoptado por Atenas y después extendido a Sicilia y zona norte del Egeo. La gran prosperidad e importancia política que fue adquiriendo Atenas contribuyó a su difusión y en época de Alejandro Magno Se usó en Atenas, Eubea, gran parte de Siclia, Delos, Cirenaica y será el que posteriormente imponga Alejandro III, el Magno en todos sus dominios. Las dracmas áticas de Nuevo Estilo pesaban en torno a 4,2 g.

Corintio: Estátera de 8,6 g, que se correspondía con una didracma ática, pero que generalmente se amonedaba con tridracmas de $8,70 \mathrm{~g}$. Con dracmas de 2,90 g. Fue usado en Corinto, Ambracia y Leucas.

Eubeo: Estátera de 17,2 g. Contempló en su sistema la creación de moneda fraccionaria con denominaciones como: tercios, sextos etc...

Campaniense o Aqueo/Itálico: Estátera de $8 \mathrm{~g}$., muy usado también en las colonias de la Magna Grecia, de ahí su nombre. Sus dracmas pesaban 3,75 g.

Samnio: Su moneda base era la tridracma de 13,10 g.

Tracio-Macedonio: Abarca todo el complejo mundo del norte de Grecia, con diferentes situaciones. Se utilizan estáteras de 9,8 g., y otras denominaciones hasta que asumió del sistema ático.

Corciro: Sistema utilizado en la isla de Corcira y que extendió por las colonias calcídicas de Sicilia (Zancle, Himera, Naxos...) que con el tiempo se acogieron al sistema ático.

Sicilia: Su sistema estaba basado en el bronce, con la litra como medida de peso básica y que equivalía a $106 \mathrm{~g}$. Su equivalente en la plata era una pieza de $0.86 \mathrm{~g}$ (similar a un quinto de una dracma ática). A partir del siglo V a. C., prácticamente toda la isla adoptó el sistema ático y por tanto la moneda de plata inició su prevalencia sobre la de bronce no sólo en valor, sino también en volumen de emisiones y utilización. Las emisiones sicilianas fueron las primeras en marcar las monedas con caracteres o símbolos que sirvieran para identificar su valor, innovación que pasaría posteriormente a Roma. Este hecho viene a enlazar directamente con la idea que sólo la moneda de bronce o aquélla que busca su correspondencia 
con ella ha resultado ser marcada con símbolos o marcas que ayudaran a identificar su valor. La estructura métrica seguida en este caso se organiza de la siguiente forma:

Pentekontalitron: 50 litras. Su valor equivalente en Grecia era de 10 dracmas áticas (decadracma) ${ }^{27}$.

Decalitra: Diez litras equivalente a una didracma.

Pentalitron: Cinco litras, equivalente a una dracma.

Dilitron: Dos litras (211,2 g.)

Litra: 12 uncias $(105,6$ g.).

Hemilitron: Media litra. 6 uncias (52,8 g.).

Pentokion: 5 uncias. Equivalente a un hemióbolo (44 g.).

Tetraonkion: 4 uncias $(35,3$ g.)

Trias: 3 uncias $(26,4 \mathrm{~g}$.

Hexante: 2 uncias $(17,6 \mathrm{~g}$.).

Onkia: Uncia ( 8,8 g.).

Imperio Persa: Basado en la estatera de oro, posteriormente llamada "Dárico", en un inicio tuvo el mismo peso que la estera de Kroisos. Asimismo realizó emisiones en plata; el "siglo" de plata, que tenía la misma equivalencia que la antigua media estátera (correspondiente a un veinteavo de dárico). Más tarde se hicieron algunos ajustes en los pesos, para mantener correspondencias correctas entre los cambios de metal. Estas monedas continuaron en uso con modificaciones mínimas durante al menos dos siglos hasta que Alejandro III derrocó al Imperio Persa.

AV.- Dárico de $8.35 \mathrm{~g}$.

AR.- Shekel de 5,35-55 g., más ligero que el lidio. La relación fue 1/20.

Fenicio: Se basaba en el Shekel de plata de 7 g., con fracciones y múltiplos, los cuales se llegaban a intercambiar por dos dracmas. El sistema lo encontramos en piezas acuñadas en Tracia, Macedonia, Cólquide, Egipto, Cirenaica y Cartago. $\mathrm{Su}$ origen debemos buscarlo entre las acuñaciones en electro de Mileto y su dracma equivalía a 3, 60 g. De este sistema evolucionará el posterior sistema púnico.

\footnotetext{
${ }^{27}$ Según escribió Diodoro en el siglo I a. C. (Biblioteca Historica) existía en Sicilia una pieza llamada Demareteion, acuñada en honor a Demarete, mujer de Gelon I de Siracusa, por la ayuda prestada para alcanzar la paz con los cartagineses tras la batalla de Himera en el 480 a. C. Sería una serie más dentro de las decadracmas siracusana (diez dracmas áticas) y se denominaría también Pentekontalitron. Hay fuentes que incluso llegan a afirmar que el retrato que aparece en estas monedas y en las decadracmas siracusanas posteriores no sería el de la ninfa Arethusa, sino el de la propia Demarete, sin embargo en la actualidad, esta identificación está prácticamente rechazada.
} 


\begin{tabular}{|l|c|c|c|}
\hline EQUIVALENCIAS & Dracmas & Óbolos & Litras \\
\hline Estátera de oro & 20 & 120 & 100 \\
\hline Dodecadracma & 12 & 72 & 60 \\
\hline Decadracma & 10 & 60 & 50 \\
\hline Octodracma & 8 & 48 & 40 \\
\hline Pentadracma & 5 & 30 & 25 \\
\hline Tetradracma & 4 & 24 & 20 \\
\hline Tridracma & 3 & 18 & 15 \\
\hline Didracma & 2 & 12 & 10 \\
\hline Dracma & 1 & 6 & 5 \\
\hline Pentóbolo & $5 / 6$ & 5 & $25 / 6$ \\
\hline Tetróbolo & $3 / 4$ & 4 & $10 / 3$ \\
\hline Trióbolo & $1 / 2$ & 3 & 2,5 \\
\hline Dióbolo & $1 / 3$ & 2 & $5 / 3$ \\
\hline Trihemióbolo & $1 / 4$ & 1,5 & $5 / 4$ \\
\hline Óbolo & $1 / 6$ & 1 & $5 / 6$ \\
\hline Tritetartemorion & $1 / 8$ & $3 / 4$ & $5 / 8$ \\
\hline Trihemitartemorion & $1 / 16$ & $3 / 8$ & $5 / 16$ \\
\hline Tetartemorion & $1 / 24$ & $1 / 4$ & $5 / 24$ \\
\hline Hemitetartemorion & $1 / 48$ & $1 / 8$ & $5 / 48$ \\
\hline
\end{tabular}

\section{CONCLUSIONES}

Como se ha visto a lo largo de estas líneas, dentro del entorno griego, la situación era diferente a lo que encontramos en los sistemas monetales posteriores, la diferencia radicaba principalmente en que se trataba de una comunidad comercial, no política, que consiguió evitar el problema del cambio monetario. Es decir la monedas surgieron en el entorno cultural de la Hélade, pero con diferentes emisiones que llegaban incluso a seguir diferentes patrones métricos, sin embargo todos mantenían una relación entre todas ellas que quedaba fijado en los santuarios y sobre todo en la pureza del metal usado. Así que el modelo resultante fue una red que abarcaba todo el Mediterráneo, conectada a través de los diferentes de patrones, y que aceptaba en ella todas las acuñaciones que tuvieran la característica de peso=valor, y esto es justamente el origen de su éxito ya que está en uso desde el siglo VII a. C. y su gran utilidad fue su gran éxito a lo largo de los siglos, hasta que fue poco a poco desplazada por otras monedas, siempre por motivos políticos más que económicos, ya que su función económica la convirtió en de uso casi universal. 
A lo largo de este trabajo hemos resaltado la relevancia adquirida por la moneda dentro del entorno mediterráneo pero no sólo por su función como medio de pago, sino también por su labor propagandística y social. Para una poleis griega el hecho de acuñar moneda era un símbolo de poderío, por lo que cuanto más se extendiesen el uso de sus monedas, más conocida sería la ciudad. Pero en ese mensaje transmitido a través de la moneda, no sólo la simbología de los tipos monetales resultaba relevante, sino también otros aspectos que transmitían su preeminencia económica, política y social como su peso y valor, el metal escogido y su calidad, o el grado de desarrollo tecnológico y artístico de esas piezas (si fueron acuñadas por anverso y reverso). Buen ejemplo de ello es el caso de Atenas, cuyas primeras emisiones datan entre el 575-540 a. C. y que tras la incorporación de nuevos estilos a finales de ese siglo VI a. C. le situó en una posición prioritaria. Pero sin duda un golpe de efecto fue el adquirido por el valor de sus piezas, la incorporación de nuevas métricas y la emisión en valores de 12 gramos fue una innovación cargada de simbolismo de potencial económico (posteriormente al adoptar el patrón beocio, las tetradracmas pasaron a pesar 16 gramos aproximadamente). Este hecho llega a su máxima expresión cuando en las zonas de minas argentíferas en el norte de Grecia, se llegan a acuñar octodracmas (32 g.) e incluso doble-octodracmas (64 g.) que pronto fueron abandonadas por su falta de utilidad para transacciones y su altísimo coste ${ }^{28}$.

En definitiva observamos que la Hélade no acuñó de forma general como hicieron civilizaciones posteriores. Sino que las emisiones se realizaban a nombre de poleis, de sus ciudadanos, ligas y federaciones ${ }^{29}$, y por último los reyes, en especial en Macedonia y luego en los reinos helenísticos. Por lo que hoy día tenemos un amplio abanico temporal y geográfico (con todas las colonias griegas emplazadas en el Mediterráneo), abarcando desde las costas nororientales de la península Ibérica y el sur de Francia hasta el valle del Indo y donde el valor de la moneda venía representado por su peso. Hay diversas denominaciones dependiendo del metal en que se acuñaba. Incluso utilizando un mismo metal, encontramos el uso de diferentes patrones puesto que las acuñaciones se hacían con plata de

\footnotetext{
${ }^{28}$ Así la moneda de plata alcanzó gran extensión por el Mediterráneo; pues cada metrópoli la intercambió, comerció y exportó monedas con otras poleis y con sus colonias que a su vez tenían también sus propias emisiones: Massalia, Emporiton y Rhode. Pero las más importantes se situaron en la zona de Magna Grecia y Sicilia.

29 Adelantándose en más de dos mil años al EURO, pero con las mismas características, en las moneda una cara con un tipo común y otra con un tipo propio, de obligada aceptación en todas las localidades de la federación.
} 
diferentes calidades, por lo que cada una se acoge a un peso distinto que regula con un sistema propio de su zona que no tiene por qué coincidir con el de otras ${ }^{30}$.

Contrario a la moneda de plata y oro, surgió la pieza de bronce, la cual circulaba sólo dentro de las ciudades y sería utilizado en las transacciones cotidianas, de hecho fuera del circulo inmediato a ellas no tenían valor. En definitiva, nos encontramos con que los diferentes sistemas métricos y los usos que podrían tener esas monedas han sido el eje conductor de este trabajo, que basándonos en la idea que la moneda fraccionaria nos muestra el grado de desarrollo de la economía de la poleis que la emite. El que fuera en los santuarios donde se localizaran estelas con referencias sobre las correspondencias en los intercambios, nos da muestra de la oficialidad de las transacciones, así como que sería desde los templos desde donde se regulase el sistema económico pues no olvidemos que también era allí donde se localizaba la ceca y donde se almacenaba la riqueza del Estado.

Un matiz que nos ha resultado interesante al analizar las piezas arcaicas, sus leyendas y tipos, es la ausencia de signos de valor. De hecho, incluso en el curioso caso de los tipos parlantes, siempre se hace referencia al origen de la emisión de las cecas pero nunca se utiliza este método para representar el valor, cuando a priori sería más funcional. Lo que nos da una importante información sobre la costumbre de pesar las piezas y el interés por incluir la propaganda en el mensaje numario. En cualquier caso no les interesó incluirlo porque debía de estar muy asumido. De hecho sólo se encontrarán símbolos de valor a lo largo de este período de la historia monetaria, cuando los sistemas métricos se basaron en el bronce y entonces sí requirieron de la mención de su valor para matizar su correspondencia con emisiones en otros metales de mayor valor ${ }^{31}$.

Para finalizar queremos destacar cómo en la Grecia antigua el propio valor de la moneda ya nos da un significado de ella misma, pues dependiendo de él su función variaba. Por ello entendemos que el valor de la moneda ha de incluirse como una referencia iconográfica, es decir como parte de su mensaje ya que los tipos monetales representados no son los mismos ni se dirigen a las mismas personas. Aun cuando podría decirse que en la antigüedad helena, a merced de este sistema de valores, con la misma moneda se podría realizar cualquier pago y esto

\footnotetext{
${ }^{30}$ De entre los diferentes valores, la dracma se posicionó como unidad básica, a partir de la cual se desarrolló un amplio sistema de denominaciones cuyo valor varió en virtud de su peso, y que al no corresponderé entre las diferentes poleis dio lugar al elenco de sistemas métricos expuesto.

${ }^{31}$ Recordemos el caso de las piezas de la República Romana y sus muy claras signos de valor en el bronce, pero también en la plata (denario) e incluso en la primera acuñación de oro (la de Marte y el águila).
} 
ANa Vico Belmonte y José María de Francisco Olmos

EL SISTEMA MONETARIO GRIEGO Y SUS DERIVACIONES A OTROS SISTEMAS DE LA ANTIGÜEDAD MEDITERRÁNEA

la convertía más que en una moneda como elemento de pago, en un instrumento de civilización. 